\title{
El zancarrón de Mahoma: un chiste antiislámico en Lope de Vega
}

The Mahoma's zancarrón: an anti-Islamic joke in Lope de Vega

\author{
Antonio Sánchez Jiménez \\ Université de Neuchâtel \\ Antonio.sanchez@unine.ch \\ ORCID iD: https://orcid.org/0000-0002-0017-9077
}

RESUMEN: Este trabajo examina un persistente chiste antiislámico que recorre la literatura del Siglo de Oro: la idea de que los musulmanes adoraban en la Meca un hueso amojamado de Mahoma que mantenían flotando por medio de unos imanes. Tras presentar los orígenes de la noticia, la rastreamos en la obra dramática de Lope de Vega, en la que estudiamos los usos que le dio el Fénix al motivo.

Palabras clave: Lope de Vega, reliquias, anti-islamismo, motivos, zancarrón, Mahoma.

ABSTRACT: This article examines a persistent anti-Islamic joke that we often find in Golden Age Spanish literature: the idea that Muslims worshipped in Mecca a drycured leg of Muhammad that they kept floating in the air thanks to the action of some magnetic stones. After examining the origins of this anecdote, we trace it in Lope de Vega's dramatic work, where we study how he used the motif.

Keywords: Lope de Vega, relics, anti-Islamism, motifs, zancarrón, Muhammad.

Uno de los chistes antiislámicos más persistentes durante el Siglo de Oro fue el del zancarrón de Mahoma, un curioso pernil amojamado que, según una tradición maliciosa, pendía en la Meca gracias a la acción de dos grandes imanes. La anécdota fue muy popular en un país como España, forjado en una relación conflictiva con el islam y, por demás, tan aficionado a las reliquias como a la mojama, cecina y jamón. Tanto llegó a difundirse la noticia acerca de la supuesta pierna milagrosa que la palabra zancarrón se usaba con mayor fre-

Copyright: (C) 2019 CSIC. Este es un artículo de acceso abierto distribuido bajo los términos de la licencia de uso y distribución Creative Commons Reconocimiento 4.0 Internacional (CC BY 4.0). 
cuencia para referirse a la reliquia del profeta que a la acepción original $(C D H$, s. v. zancarrón) $)^{1}$, esto es, al 'pie enjuto sin carne' (Covarrubias, 2006: s. v. zanca), al 'hueso del pie desnudo y sin carne' (Diccionario de Autoridades, 1726-1737: s. v. zancarrón). No en vano, el Diccionario de Autoridades honra este uso que nos interesa con la entrada Zancarrón de Mahoma, que reza: 'llaman por irrisión los huesos de este falso profeta, que van a visitar los moros a la mezquita de la Meca' y que ilustra con un romance de la musa sexta de Quevedo. El furor por el zancarrón todavía colea en el siglo XVIII, según muestra el CORDE (s. v. zancarrón), donde encontramos usándolo a un autor tan inclinado a la sátira como el padre Isla ${ }^{2}$. Sin embargo, los zancarrones caerían en claro declive en el siglo siguiente, en el que el duque de Rivas censura, en $E l$ moro expósito, que unos cristianos despechados caigan en contar "chistes de alcuzcuz, zancarrón y otras sandeces" (Davies, 2001-2017: s. v. zancarrón) $)^{3}$. El resultado de la caída en desgracia del zancarrón es que la palabra resulta extraña hoy a la mayoría de los hispanohablantes, que, si la conocen, la asociarán más bien con un guisado de ternera o cordero que con el chiste antiislámico.

Por tanto, el Siglo de Oro de las letras también fue la época dorada del zancarrón de Mahoma, que asoma desde el Viaje de Turquía (2000: 662) ${ }^{4}$ y la obra de Bartolomé Torres Naharro (2013: 872) ${ }^{5}$ a la de sor Juana Inés de la Cruz, gozando de la especial devoción de Francisco de Quevedo $(C D H, s . v$. zancarrón), como quizás cabría esperar. Centrándonos en este periodo, nuestro trabajo estudia los usos de este chiste en la obra dramática de Lope de Vega, autor que también fue muy aficionado a sacar a relucir la grotesca reliquia. Para ilustrar el modo en que la empleaba en sus comedias, estudiaremos en

\footnotetext{
${ }^{1}$ De 51 ocurrencias en textos áureos, solo 13 no se refieren al zancarrón de Mahoma, de las cuales 6 se encuentran en la Historia verdadera de Bernal Díaz del Castillo $(\mathrm{CDH}, s$. v. zancarrón).

2 También lo usaron en el siglo ilustrado escritores como Vicente Rodríguez de Arellano (CDH, s. v. zancarrón), o el anónimo autor del pliego suelto que estudia Ceballos Viro (2009). Gillet (1951: 769) lo localiza asimismo en un texto de la Guatemala del siglo XVIII.

${ }^{3}$ Sin embargo, un autor reaccionario e interesado en las tradiciones orales como Fernán Caballero (Cecilia Böhl de Faber) todavía lo usa en 1836, en Genio e ingenio del pueblo andaluz: "Mira el moro siendo infiel / cuál entra con atención / descalzo por su mezquita / y adora a un zancarrón". De modo semejante, José María de Pereda lo saca a colación en La Puchera (1870) (Davies, 2001-2017: s. v. zancarrón).

${ }^{4}$ En el Viaje de Turquía la reliquia es más bien un zapato, pues Pedro de Urdemalas (2000: 662) explica que en la Meca muestran "no más del sepulchro y un çapato dorado suyo, llamado isaroh, que está colgado". Gillet (1951: 767) encontró el motivo del zancarrón en textos anteriores, como el Diálogo e razonamiento en la muerte del marqués de Santillana, de Pero Díaz de Toledo.

${ }^{5}$ En la Comedia Aquilana Torres Naharro (2013: vv. 1655-1656) menciona los "grandes zancarrones / de los santos Doce Pares", lo que solo alude indirectamente a Mahoma, pues, como indica en nota el editor de la obra, Julio Vélez Sainz, el vocablo sugería automáticamente el mahometismo, según comprobaremos en este artículo.
} 
primer lugar la naturaleza y recorrido del zancarrón en la época. Tras esta introducción presentaremos nuestra metodología, que le debe mucho a tres bases de datos (el CORDE, el $C D H$ y el TESO). Completando los resultados que ellas nos proporcionan, en la parte central del trabajo estableceremos una serie de taxonomías que ilustran qué veía Lope en esta mojama flotante y que nos permitirán esbozar una serie de conclusiones de mayor amplitud en los párrafos finales del trabajo.

La mejor explicación acerca de la naturaleza del zancarrón de Mahoma la encontramos en una obra del propio Lope, Los esclavos libres. Concretamente, se localiza en una escena en la que dos pajes que están burlándose del morisco Zulemilla cuentan la ignominiosa muerte del profeta islámico y el origen de la adoración de su zancarrón:

\begin{tabular}{|c|c|}
\hline & $\begin{array}{l}\text { ¿De qué suerte, } \\
\text { Guzmán, en Meca está el pernil mohoso } \\
\text { del señor don Mahoma? }\end{array}$ \\
\hline PAJE 3 & $\begin{array}{l}\text { Enamorado } \\
\text { dicen que andaba este bestial profeta } \\
\text { de una judía, y el marido y padres } \\
\text { cogiéronle entre puertas, como a perro, } \\
\text { y diéronle paliza temeraria; } \\
\text { viéndole muerto, hiciéronle pedazos, } \\
\text { reservando una pierna y la cadera, } \\
\text { rogando a la judía que dijese } \\
\text { que una noche, gozándola, se había } \\
\text { subido al cielo, y que ella, por tenerle, } \\
\text { le asió de aquella pierna, que en reliquias } \\
\text { le dejó, y se llevó lo más del cuerpo. } \\
\text { Creyéronlo los moros, y escapáronse } \\
\text { de ellos, con este engaño, los judíos; } \\
\text { tomaron, pues, la pierna, y allá en Meca, } \\
\text { entre piedras imanes la pusieron, } \\
\text { cuya virtud la tiene y la sustenta, } \\
\text { aungue ellos niensan }\end{array}$ \\
\hline
\end{tabular}

ZULEMA

¡Ah, berros, de Mahoma decer beliaquerías! (Vega Carpio, 2014b: vv. 2769-2789).

Como explican los tres estudios que conocemos sobre el zancarrón (Ceballos Viro, 2009; Domínguez, 1985; Perceval, 1988), el motivo circulaba en diversas versiones ligeramente divergentes. La de Lope es una de las más completas, pues explica cómo la deshonrosa muerte de Mahoma a manos de los judíos (inversión denigrante de la pasión de Cristo) resultó en una falsa reliquia: una pierna amojamada que se muestra en la Meca mediante un fraude tecnológico que la hace levitar, simulando poderes milagrosos. Otras versiones difieren en lo relativo a las postrimerías del profeta y explican cómo, al sentirse 
morir, Mahoma anunció que el arcángel Gabriel vendría para llevarle a los cielos. Sin embargo, la profecía no se hizo realidad:

Murió el desdichado, cuyo miserable cuerpo guardaron los suyos tres días, por ser testigos de su resurrección. Pero viendo que no resucitaba dentro los tres días, presumieron que Gabriel, a quien según ellos pensaban había Dios encomendado el resucitalle, se había enfadado de ver tantos presentes al caso, que era bien se hiciese en secreto; y así se retiraron y dejaron el cuerpo de Mahoma solo. Apenas le dejaron, cuando le hicieron compañía, no ángeles, sino infinitos perros que acudieron al hedor de la carne y le abrieron el costado. Esta fue la lanzada que le dieron, para que manasen los falsos sacramentos y ceremonias alcoranas. Pasados días volvieron sus discípulos y harto maravillados y afligidos del caso enterraron aquellas infelices reliquias que dejaron los perros. [...] Quien quisiere ver más copiosamente las bestialidades que enseñó Mahoma, lea a san Damasceno, De Haeresibus, a la fin; a san Eulogio, de quien es casi todo lo que he dicho en este capítulo; a Euthymio, y a otros muchos modernos. Lo que comúnmente dicen, que en la casa de Meca están sus huesos en el aire en una arquilla de hierro por virtud de las opuestas imanes, no es imposible, pues con el mesmo artificio tuvieron los gentiles en el aire el ídolo del sol (Verdú, 1612: ff. 134r-135r).

La extensa cita resulta necesaria porque en ella Verdú presenta varios elementos muy importantes para entender la leyenda. El primero de ellos es su representación de Mahoma y de la religión islámica en general como una absurda parodia de Jesucristo y el cristianismo. Se trata de un modo de pensamiento muy extendido y en absoluto circunscrito a la leyenda del zancarrón, como podemos comprobar, por ejemplo, al ver que durante la Edad Media cristiana se entendía que los musulmanes adoraban a una especie de Trinidad diabólica que componían Apolo, Mahoma y Tervagán (o Termagante) (Cantar de Roldán, 1983: vv. $7-8,416-417,3267-3268)^{6}$. En el caso que nos ocupa, este paralelismo entre cristiandad e islam explica diversas referencias del texto de Verdú sobre el origen del zancarrón: las menciones a la fallida resurrección de Mahoma tres días después de morir, a su igualmente frustrada ascensión a los cielos y a la apertura de su costado. Y la contraposición de las dos religiones explica también la existencia del propio zancarrón, pues este "pernil mohoso" funciona como una reliquia grotesca: en contraste con lo que debería ser una verdadera reliquia (por supuesto, cristiana), el zancarrón es el recuerdo de una muerte deshonrosa, no ejemplar, no tiene poder alguno y encima está medio corrupta, lo que muestra la falta de santidad de su dueño. No se trata, pues, de que los españoles áureos no pudieran concebir la existencia de un mundo sin reliquias, como señala Perceval (1988), sino de que idearon esta para denigrar a los musulmanes. Esta

\footnotetext{
${ }^{6}$ Sobre la identificación de los musulmanes con los paganos idólatras durante la Edad Media, ver Tolan (1999).
} 
intención islamófoba ${ }^{7}$, a veces relacionada con los moriscos y su expulsión, es el segundo elemento de importancia que nos transmite el texto de Verdú, que no en vano contiene un "Discurso de la expulsión de los moriscos de España": el zancarrón y el odio a los moriscos a veces iban de la mano, aunque no siempre era así, como veremos abajo. En tercer lugar, Verdú es interesante porque nos proporciona las fuentes de estas noticias sobre la muerte y reliquias del profeta. Según aclara Fernando de la Granja (1968: 345-346), beben de una leyenda de tiempos de la cuarta y quinta cruzada de acuerdo con la cual el Anticristo aparecería cuando cayese el ídolo de Mahoma que se guarda colgado con piedras de imán en la $\mathrm{Meca}^{8}$. Esta historia dio lugar a toda una tradición de polemistas cristianos - Pedro el Venerable, Mateo de París, Vicente de Beauvais, Ramón Martí, Pedro Pascual - que alteraba la información que encontraba en las fuentes islámicas para presentar una versión infamante y azancarronada de la muerte de Mahoma (Ceballos Viro, 2009: 306; Tolan, 2009 y 2010). De ella se alimentaron gustosamente nuestros autores áureos.

Y es que, como hemos avanzado, la leyenda fue muy popular en el Siglo de Oro. Concretamente, gozó de gran fortuna en las tablas, hasta el punto de que encontramos menciones al zancarrón en obras dramáticas como la Comedia Aquilana de Torres Naharro, arriba citada, y en varios coloquios de González de Eslava. Si recurrimos a las bases de datos habituales, comprobamos que el CORDE solo arroja un ejemplo teatral de zancarrón, Viuda, casada y doncella, de Lope, que veremos abajo. Sin embargo, el Corpus del Diccionario Histórico $(\mathrm{CDH})$ trae ya varios casos: el Coloquio del bosque divino, el Coloquio de la batalla naval y el Coloquio espiritual de la pobreza y la riqueza, de González de Eslava, El alcalde mayor y San Diego de Alcalá de Lope, El doctor Carlino, de Góngora, La virgen de los Reyes, de Hipólito de Vergara y El príncipe constante, de Calderón de la Barca. Son datos que ya destacan el protagonismo de Lope, que además confirma una base de datos especializada en dramaturgia áurea: el TESO. Una búsqueda en ella arroja quince comedias con zancarrones, de las cuales tres son de Calderón (El príncipe constante, Amar después de la muerte y El jardín de Falerina), dos de Rojas Zorrilla (Nuestra Señora de Atocha, El profeta falso Mahoma), una de Pérez de Montalbán (El valiente más dichoso), una de Moreto (La fuerza de la ley), una de Matos Fragoso (El amor hace valientes) y una de Juan Bautista Diamante (Santa María del Monte y convento de San Juan). El resto (cinco, un 33.3 \%) son de Lope: El alcalde

\footnotetext{
${ }^{7}$ Sobre las polémicas contra el islam en el Siglo de Oro, y en concreto acerca del papel que en ellas desempeñó la vida de Mahoma, véase Bunes Ibarra (1989: 213).

${ }^{8}$ Ver también, sobre el surgimiento de la leyenda, Tolan (1998). Gillet (1951: 758), citando a D'Ancona (1889: 250), traza un origen preciso a partir del manuscrito Liber Nycolay qui dicitur Macumetus.
} 
mayor, Los esclavos libres, El favor agradecido, El valiente Céspedes y Viuda, casada y doncella. Limitándonos ya al corpus lopesco, que obviamente resulta el más fecundo en zancarrones, hemos completado la búsqueda añadiendo otras palabras clave relacionadas con la reliquia. Así, preguntando por "Mahoma", "Meca" y "pernil" aparecen mencionados los huesos flotantes del profeta en Angélica en el Catay, La boba para los otros y discreta para sí, La campana de Aragón, El cerco de Santa Fe, El cuerdo loco, El hidalgo Bencerraje, Lo que hay que fiar del mundo, El primer Fajardo, La Santa Liga y El sol para$d o$, que añadidas a las cinco comedias anteriores dan un corpus de quince obras. Además, a ellas podemos sumar zancarrones que no aparecen en esta base de datos, pues los hemos localizado también en La pobreza estimada, Los Porceles de Murcia, El remedio en la desdicha, Los mártires de Madrid, Los Vargas de Castilla, San Diego de Alcalá (ya presente en el CORDE, pero no en el TESO), Ya anda la de Mazagatos y La difunta pleiteada ${ }^{9}$. Son, pues, ocho obras más que, junto a las anteriores, conforman nuestro corpus definitivo de veintitrés comedias lopescas.

Podemos presentar estos datos como sigue, ordenando cronológicamente las comedias ${ }^{10} \mathrm{y}$ especificando a qué subgénero dramático pertenecen ${ }^{11}$. A ello añadimos otras variables: qué tipo de personaje enuncia la referencia al zancarrón, con qué palabra se refiere a él y en qué clase de metro (de arte mayor o menor):

\begin{tabular}{|c|c|c|c|c|c|}
\hline Años & \begin{tabular}{|l|} 
Título \\
\end{tabular} & Subgénero & \begin{tabular}{|l|} 
Personaje \\
\end{tabular} & \begin{tabular}{|l|} 
Expresión \\
\end{tabular} & Metro \\
\hline 1593 & $\begin{array}{l}\text { El favor agradecido } \\
\text { (Vega Carpio, 2016a: vv. } \\
2244-2260)\end{array}$ & Palatina & $\begin{array}{l}\text { Criado (disfrazado } \\
\text { de moro) }\end{array}$ & Zancarrón & Arte menor \\
\hline $\begin{array}{l}\text { c. } 1593- \\
1595\end{array}$ & $\begin{array}{l}\text { La difuma pleiteada } \\
\text { (Vega Carpio, } 1917 \mathrm{a}: \\
559)\end{array}$ & $\begin{array}{l}\text { Urbana (con episo- } \\
\text { dios en Argel) }\end{array}$ & $\begin{array}{l}\text { Galán (disfrazado } \\
\text { de moro) }\end{array}$ & Zancarrón & Arte menor \\
\hline 1596 & $\begin{array}{l}\text { El remedio en la desdicha } \\
\text { (Vega Carpio, } 1900 \mathrm{~b}: \\
175 \text { ) }\end{array}$ & Hechos famosos & Soldado gracioso & Zancarrón & Arte menor \\
\hline $\begin{array}{l}\text { c. } 1596- \\
1603\end{array}$ & $\begin{array}{l}\text { El sol parado (Vega Car- } \\
\text { pio, } 1899 b: 49 \text { ) }\end{array}$ & Hechos famosos & Rey moro & Huesos & Arte mayor \\
\hline $\begin{array}{l}\text { c. } 1597- \\
1603\end{array}$ & $\begin{array}{l}\text { La pobreza estimada } \\
\text { (Vega Carpio, en prensa } \\
\text { b: f. } 39 \mathrm{~V} \text { ) }\end{array}$ & $\begin{array}{l}\text { Urbana y de cauti- } \\
\text { vos }\end{array}$ & Galán & Huesos & Arte menor \\
\hline $\begin{array}{l}\text { c. } 1598- \\
1600\end{array}$ & $\begin{array}{l}\text { La campana de Aragón } \\
\text { (Vega Carpio, en prensa } \\
\text { a: f. 218r) }\end{array}$ & Hechos famosos & Alcaide moro & Huesos & Arte mayor \\
\hline $\begin{array}{l}\text { c. } 1598- \\
1600\end{array}$ & $\begin{array}{l}\text { La Sania Liga (Vega } \\
\text { Carpio, 2016b: vv. 2767- } \\
\text { 2768) }\end{array}$ & Hechos famosos & Uchalí & Huesos & Arte mayor \\
\hline $\begin{array}{l}\text { c. } 1599 \\
1603\end{array}$ & $\begin{array}{l}\text { La divina vencedora } \\
\text { (Vega Carpio, 1917b: p. } \\
625 \text { ) }\end{array}$ & Hechos famosos & $\begin{array}{l}\text { Gallinato (general } \\
\text { cristiano) }\end{array}$ & Zancarrón & Arte menor \\
\hline
\end{tabular}

${ }^{9}$ Algunas de estas obras aparecen mencionadas en Herrero García (1966: 582-583).

${ }^{10}$ Seguimos las fechas que proporcionan Morley y Bruerton (1968).

${ }^{11}$ No hemos hecho distinción, en las comedias historiales, entre las de hechos particulares y famosos, pues ambas tienen relación con la comedia genealógica y se mezclan. Sobre la comedia genealógica, véase Ferrer (1993 y 2001). 


\begin{tabular}{|c|c|c|c|c|c|}
\hline $\begin{array}{l}\text { c. } 1599- \\
1603\end{array}$ & $\begin{array}{l}\text { Los esclavos libres (Vega } \\
\text { Carpio, 2014b: vv. 2756- } \\
\text { 2789) }\end{array}$ & Cautivos & Paje & $\begin{array}{l}\text { Zancarrón, } \\
\text { pernil }\end{array}$ & Arte menor \\
\hline c. 1599 & $\begin{array}{l}\text { Angélica en el Catay } \\
\text { (Vega Carpio, 2009: vv. } \\
\text { 2620-2622) }\end{array}$ & Caballeresca & Rodamonte & Huesos & Arte mayor \\
\hline c. 1600 & $\begin{array}{l}\text { Viuda, casada y doncella } \\
\text { (Vega Carpio, } 2008 \mathrm{c}: \mathrm{vv} \\
\text { 1394-1400) }\end{array}$ & $\begin{array}{l}\text { Urbana (con episo- } \\
\text { dios en Argel) }\end{array}$ & $\begin{array}{l}\text { Galán (disfrazado } \\
\text { de médico en Ar- } \\
\text { gel) }\end{array}$ & Zancarrón & Arte menor \\
\hline 1602 & $\begin{array}{l}\text { El cuerdo loco (Vega } \\
\text { Carpio, 2015: vv. 1488- } \\
\text { 1491) }\end{array}$ & Palatina & Sultán & Huesos & Arte mayor \\
\hline $\begin{array}{l}\text { c. } 1602- \\
1606\end{array}$ & $\begin{array}{l}\text { Los mártires de Madrid } \\
\text { (Vega Carpio, [965: 252) }\end{array}$ & De santos & Gran Turco & Zancarrón & Arte menor \\
\hline $\begin{array}{l}\text { c. } 1604- \\
1612\end{array}$ & $\begin{array}{l}\text { El alcalde mayor (Vega } \\
\text { Carpio, 2014a: vv. 1615- } \\
\text { 1622) }\end{array}$ & Urbana & Criado gracioso & Zancarrón & Arte menor \\
\hline $\begin{array}{l}\text { c. } 1605- \\
1608\end{array}$ & $\begin{array}{l}\text { Los Porceles de Murcia } \\
\text { (Vega Carpio, 2008b: vv. } \\
\text { 2739-2742) }\end{array}$ & Hechos famosos & Villano & Zancarrón & Arte menor \\
\hline $\begin{array}{l}\text { c. } 1605- \\
1606\end{array}$ & $\begin{array}{l}\text { El hidalgo Bencerraje } \\
\text { (Vega Carpio, 1900a: } 65 \text { ) }\end{array}$ & Hechos famosos & $\begin{array}{l}\text { Zulema (morisco } \\
\text { gracioso) }\end{array}$ & Zancajo, pernil & Arte menor \\
\hline c. 1610 & $\begin{array}{l}\text { Lo que hay que fiar del } \\
\text { mundo (Vega Carpio, } \\
\text { 2008a: vv. 1676-1685) }\end{array}$ & Hechos famosos & $\begin{array}{l}\text { Criador gracioso } \\
\text { (vestido de turco) }\end{array}$ & Huesos & Arte menor \\
\hline $\begin{array}{l}\text { c. } 1610- \\
1612\end{array}$ & $\begin{array}{l}\text { El primer Fajardo (Vega } \\
\text { Carpio, 1899a: pp. } 5,17 \text { y } \\
\text { 20) }\end{array}$ & Hechos famosos & $\begin{array}{l}\text { Abenaljáfar; Fajar- } \\
\text { do; Zulemilla (mo- } \\
\text { risco gracioso). }\end{array}$ & $\begin{array}{l}\text { Cuerpo; hue- } \\
\text { sos; zancarrón. }\end{array}$ & $\begin{array}{l}\text { Arte menor; arte } \\
\text { menor; arte me- } \\
\text { nor. }\end{array}$ \\
\hline $\begin{array}{l}\text { c. } 1610- \\
1615\end{array}$ & $\begin{array}{l}\text { Los Vargas de Castilla } \\
\text { (Vega Carpio, } 1899 \mathrm{c} \text { : } \\
\text { 303) }\end{array}$ & Hechos famosos & Soldado & Profeta & Arte menor \\
\hline $\begin{array}{l}\text { c. } 1612- \\
1615\end{array}$ & $\begin{array}{l}\text { El valiente Céspedes } \\
\text { (Vega Carpio, 1901:201) }\end{array}$ & Hechos famosos & Criado gracioso & Zancarrón & Arte menor \\
\hline 1613 & $\begin{array}{l}\text { San Diego de Alcalá } \\
\text { (Vega Carpio, 1895: 56) }\end{array}$ & De santos & $\begin{array}{l}\text { Alí (morisco gra- } \\
\text { cioso) }\end{array}$ & Zancarrón & Arte menor \\
\hline c. 1630 & $\begin{array}{l}\text { La boba para los otros y } \\
\text { discreta para si (Vega } \\
\text { Carpio, 1929:501) }\end{array}$ & Palatina & $\begin{array}{l}\text { Gracioso (vestido } \\
\text { de turco) }\end{array}$ & Pernil & Arte menor \\
\hline s. f. & $\begin{array}{l}\text { Ya anda la de Mazagatos } \\
\text { (Vega Carpio, } 1930: 527 \text { ) }\end{array}$ & Hechos famosos & Gracioso & Zancarrón & Arte menor \\
\hline
\end{tabular}

Estos datos nos permiten presentar ya algunas conclusiones. En primer lugar, observamos que la mayor parte de los testimonios corresponde a la época más fecunda de Lope, su producción del reinado de Felipe III, que reúne un $78 \%$ de menciones. Esto podría sugerir, en segundo lugar, que la afición a los zancarrones se relaciona con la polémica antimorisca, que fue especialmente encendida durante este gobierno, que fue el que llevó a cabo la expulsión de los moriscos en 1609. Sin embargo, solo ocho obras (35\%, poco más de un tercio) datan de los años inmediatamente anteriores y posteriores a esta fecha, el cénit de la controversia, por lo que debemos concluir que el éxito de las referencias al zancarrón era en cierta medida independiente de la polémica sobre los moriscos. En tercer lugar, vemos que el corpus consta principalmente de obras historiales (doce comedias de hechos famosos, es decir, un $52 \%$, y dos de santos, un $8 \%$ ), acompañadas por urbanas (cuatro, un $17 \%$ ) y palatinas (tres, un $13 \%$ ), con una caballeresca y una de cautivos, distribución que resulta 
lógica si pensamos que la mayoría de estos pasajes se da en obras en las que hay personajes moros, que obviamente resultan mucho más abundantes en las comedias sobre la Reconquista. En cuarto lugar, observamos que estas menciones aparecen mayoritariamente en parlamentos en arte menor, con las excepciones de El sol parado, La campana de Aragón, La Santa Liga, Angélica en el Catay y El cuerdo loco. Estos cinco son casos ligados a la posición social y la religión de los personajes que mencionan la reliquia, que son siempre figuras importantes y musulmanes. Así, el que la saca a relucir en El sol parado es el rey moro Zaro:

¡Cómo! Maestre ¿sois aquel cruzado por quien vuestro Patrón, con armas de oro, dejó a Jerez el campo ensangrentado? ¡Que por los huesos que hoy en Meca adoro, que apenas me sentara a vuestro lado, que viendo una cruz desas quedo ciego, desde que vi la del Patrón gallego! (Vega Carpio, 1899b: 49).

Por su parte, el personaje que la menciona en La campana de Aragón es un alcaide moro:

Conocile en las armas, y te juro por los huesos que Meca en honra tiene que derribaba moros con la espada como el que siega con la hoz espigas, cuyos manojos recogió la muerte. (Vega Carpio, en prensa a: f. 218r).

En La Santa Liga es el célebre Uchalí, reis de la flota turca:

¡Llevadme a Argel —reniego de Mahoma-

o a Meca, porque allí sus huesos coma! (Vega Carpio, 2016b: vv. 2767-2768).

En Angélica en el Catay, es el no menos famoso, aunque ficticio, Rodamonte:

Yo juro por Mahoma y por los huesos, que en Meca penden en el aire solo, de no apartarme desta pobre ermita. (Vega Carpio, 2009: vv. 2620-2622).

Y, finalmente, en El cuerdo loco es el sultán turco que quiere colaborar para expulsar del trono al protagonista:

Pues yo juro

por los huesos que están colgando en Meca

del aire mismo, en su virtud, de darte

favor, aunque no fuera interés mío. (Vega Carpio, 2015: vv. 1488-1491). 
De estos casos podemos deducir una quinta conclusión, también relacionada con el decoro: estos personajes no pronuncian la palabra zancarrón, que Lope relega a escenas abiertamente cómicas y en arte menor. Es decir, aunque la mención del zancarrón persiguiera siempre efectos cómicos (Ceballos Viro, 2009: 307-308) - lo que explica que aparezca de preferencia en pasajes en arte menor-, el Fénix podía aludir a la reliquia con perífrasis más dignas, como las referidas a los huesos de Mahoma de estas cinco comedias citadas.

Si estudiamos en más profundidad el resto de menciones, las que se encuentran en versos en arte menor, también encontramos patrones de interés. Así, comprobamos que la mayoría se inscribe en el contexto de un juramento $^{12}$, como el que hemos visto en boca de Zaro, Rodamonte y el sultán, arriba, o como estos parlamentos de Zulema y Abenaljáfar, en El hidalgo Bencerraje y El primer Fajardo, respectivamente:

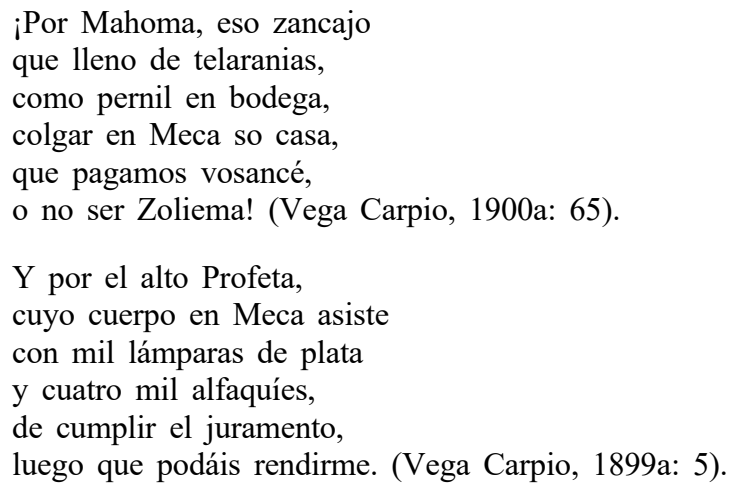

Especialmente interesante en este sentido es una escena de Lo que hay que fiar del mundo en la que el sultán Selín le pide al criado gracioso Gonzalo, que está vestido de turco, que jure que mantendrá un secreto:

\begin{tabular}{|c|c|}
\hline SELÍN: & $\begin{array}{l}\text { Júralo pues. } \\
\text { Dime juramento alguno. }\end{array}$ \\
\hline GONZALO: & $\begin{array}{l}\text { Por los huesos mahomiles, } \\
\text { que están en Meca, señor, } \\
\text { de no decirlo. }\end{array}$ \\
\hline SELÍN: & $\begin{array}{l}\text { En rigor, } \\
\text { allá los tenéis más viles. } \\
\text { Jura al Señor de tu ley. }\end{array}$ \\
\hline
\end{tabular}

\footnotetext{
${ }^{12}$ Un ilustre precedente para esta práctica es Torres Naharro (2013: 872), cuya mención del zancarrón también se da en un juramento.
} 
SELÍN:

Bien está,

advierte que es Dios Alá,

y que yo soy hombre y rey. (Vega Carpio, 2008a: vv. 1676-1685).

Gonzalo jura imitando la fórmula que hemos visto en los magnates musulmanes citados arriba (Zaro, Uchalí, Rodamonte, etc.), y que Lope usaba para caracterizar la lengua de los moros y turcos cuando pronunciaban un juramento solemne. Sin embargo, y pese a que, por supuesto, Gonzalo no se atreve a mencionar zancarrones ni perniles delante del sultán, este no considera respetuosa la alusión. Inmediatamente, compara favorablemente la reliquia de Mahoma con las que guarda la cristiandad, le pide a Gonzalo un nuevo juramento y acaba recordándole al cristiano con quién está hablando: con un hombre y un rey, es decir, con alguien valiente y poderoso, dispuesto a vengar cualquier afrenta a su religión. En suma, y por volver a las estadísticas, estos juramentos zancarroniles ocurren en un total de 7 comedias, un $30 \%$, aunque hay dos de ellos en El primer Fajardo.

Amén de los juramentos, otra escena o "paso"13 que se repite en las comedias de nuestro corpus es el del disfraz de moro o turco, vistiendo el cual un personaje alude cómicamente al zancarrón. Acabamos de ver un ejemplo en $L o$ que hay que fiar del mundo, pero encontramos otros en obras como La difunta pleiteada. Allí, Manfredo, el galán, se ha disfrazado de moro y le ha dado a Calixto una piedra que, se supone, tiene virtudes. Calixto, un escudero viejo que vigila a la dama de la que se ha enamorado Manfredo, se enfada por los nulos resultados que produce el talismán y lo compara con el zancarrón:

\begin{tabular}{|c|c|}
\hline CALIXTO: & $\begin{array}{l}\text { Mas decid, ¿qué piedra es esta } \\
\text { para remediar la vista, } \\
\text { que me distes por gran fiesta, } \\
\text { que por más que en ella asista } \\
\text { menos veo y más me cuesta? }\end{array}$ \\
\hline MANFREDO: & $\begin{array}{l}\text { Si el mal no se cura y doma, } \\
\text { no se atribuya al poder, } \\
\text { que es con la fe que se toma. }\end{array}$ \\
\hline CALIXTO: & $\begin{array}{l}\text { Reliquia debe de ser } \\
\text { del zancarrón de Mahoma; } \\
\text { basta que voy viendo menos. }\end{array}$ \\
\hline MANFREDO: & $\begin{array}{c}\text { De su virtud están llenos } \\
\text { los libros. (Vega Carpio, 1917a: 559). }\end{array}$ \\
\hline
\end{tabular}

Mucho más característica resulta la aparición del paso en La boba para los otros y discreta para sí, pues combina tres mecanismos cómicos muy habituales

${ }^{13}$ Sobre los pasos y sus repeticiones en el teatro áureo, véase Pedraza Jiménez (2008: 258, 266-267) y Sánchez Jiménez (2012 y 2014), para Lope, y de la Granja (2000) y Hernando Morata (2012), para Calderón. 
en el corpus: el disfraz de moro o turco, la referencia al zancarrón y las bromas que lo presentan como un equivalente (asqueroso) de los perniles con que se alimentan los cristianos. En la obra, Fabio, criado gracioso, está disfrazado de embajador turco y manifiesta su hambre:

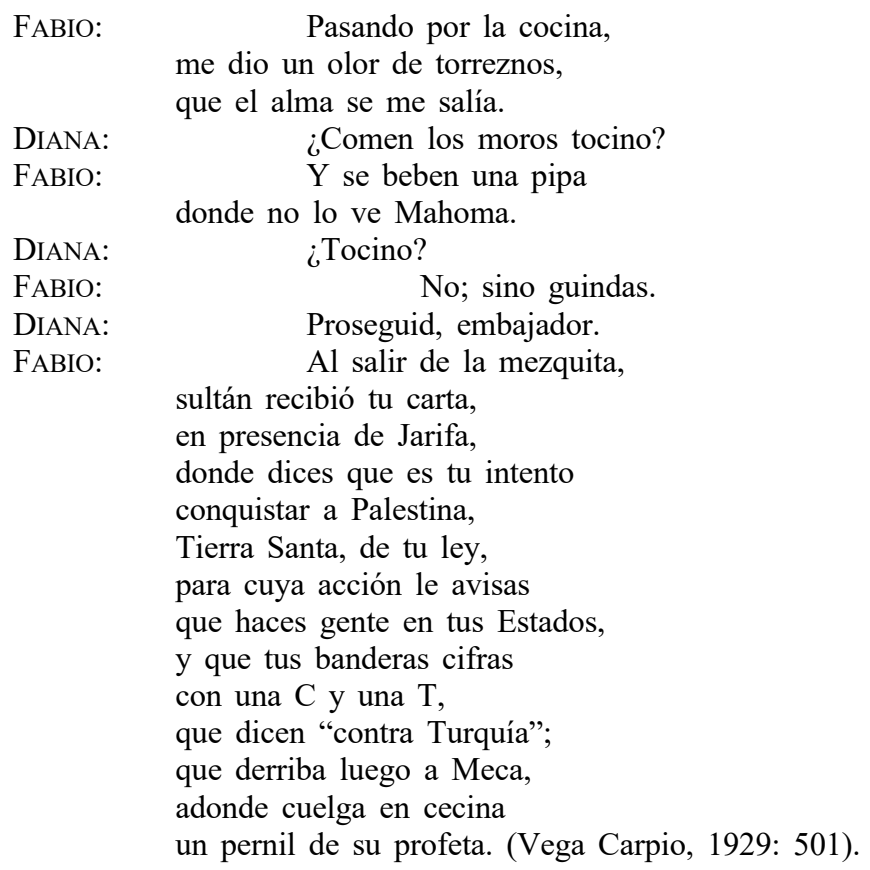

Una escena semejante la encontramos en El favor agradecido, donde el criado Pinelo se ha disfrazado de moro, pese a lo que se muestra dispuesto a beber vino y comer cerdo, contraviniendo muy a gusto la ley islámica:

$\begin{array}{lc}\text { PINELO: } & \text { Vamos, buen conde, a la cava, } \\ \text { ESTACIO: } & \text { que tengo un poco que hacer. } \\ \text { PINELO: } & \text { ¿A la cava? ¿Bebéis vino? } \\ & \text { He de comerme un tocino } \\ \text { ESTACIO: } & \text { y un cuero me he de beber. } \\ \text { PINELO: } & \text { ¿Cómo? } \\ \text { ESTACIO: } & \text { Porque allá en mi tierra } \\ \text { PINELO: } & \text { ¿No se bebe allá ninguno? } \\ & \text { Ni se coge ni se encierra; } \\ \text { ESTACIO: } & \text { en pasas nos lo dan todo. } \\ \text { PINELO: } & \text { ¿Qué moro de buen humor! } \\ & \text { Si bebo, estaré mejor; } \\ & \text { luego a un rincón me acomodo. } \\ \text { ¿Habrá pernil? }\end{array}$




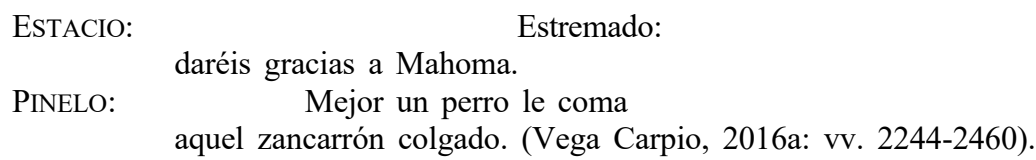

En estos casos, la contraposición entre jamón y zancarrón sirve tanto para denigrar la supuesta reliquia, el "pernil mohoso / del señor don Mahoma" (Vega Carpio, 2014b: vv. 2770-2771), como para sacar a relucir todo un clásico de la literatura antiislámica: las prohibiciones alimentarias.

No son más amables con el islam aquellos pasajes en los que un personaje musulmán reniega de su fe maldiciendo las reliquias de Mahoma. Ya hemos visto un caso en el parlamento de Uchalí tras la derrota de Lepanto en La Santa Liga, pero encontramos otro en San Diego de Alcalá. En esa comedia, Alí, morisco gracioso, es testigo de un milagro del santo, que consigue sacar vivo a un niño de un horno encendido. Esto hace exclamar al morisco:

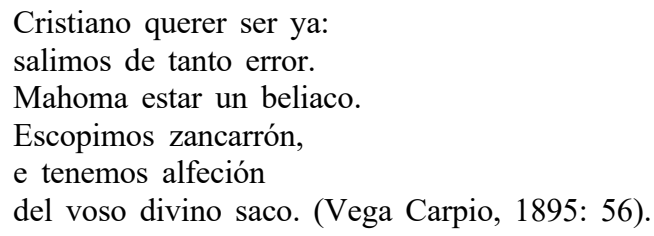

Estas maldiciones a la religión islámica y a su principal reliquia serían doblemente eficaces y cómicas por aparecer en boca de personajes musulmanes. Además, en el caso de Alí, nos revelan un clásico de la comedia áurea: el morisco gracioso. Se trata de un tipo que ha merecido un estudio individual (Case, 1981) y que aparece en varias de estas obras zancarronescas de Lope: junto a Alí debemos considerar al Zulema de Los esclavos libres, al personaje homónimo de El hidalgo Bencerraje y al Zulemilla de El primer Fajardo, todos los cuales protagonizan sendas escenas en las que se saca a relucir el zancarrón.

Para poder concluir, resumamos las otras apariciones del motivo del zancarrón de Mahoma en el corpus que hemos presentado, apariciones que resultan más difíciles de categorizar. Destaca por su originalidad la de La pobreza estimada, pues se evoca solo por alusión y cuando un personaje cristiano, el galán, trata de honrar a un musulmán, el rey de Argel, cuya decisión le ha favorecido en su pretensión amorosa:

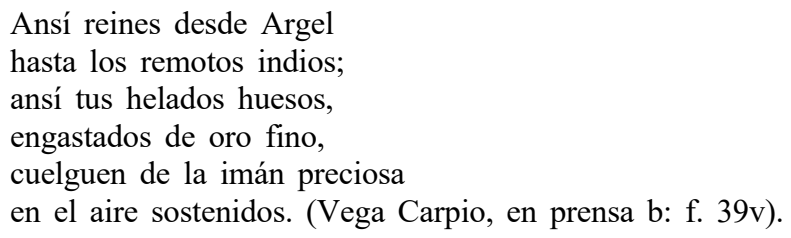


El entusiasmo del joven resulta cómico, pero lo más habitual es que Lope busque la risa con insultos directos a los moros, como ocurre en comedias como La divina vencedora, donde el general cristiano Gallinato les reprende a dos moros su falta de ceremonia al entrar a verle:

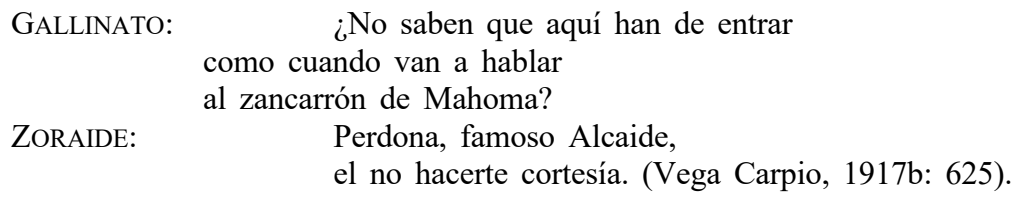

E igualmente agresivas resultan las apariciones de la reliquia en otras comedias ambientadas en tiempos de los moros, como Viuda, casada y doncella, Los Porceles de Murcia, Los Vargas de Castilla y Ya anda la de Mazagatos. Además, el zancarrón nos remite a un terreno que puede incluir otras bromas grotescas que suelen ser patrimonio del gracioso, como ocurre en este pasaje de $E l$ alcalde mayor, donde el gracioso Beltrán le pide albricias a su amo con referencias escatológicas en las que mezcla los asendereados huesos del profeta:

Dame albricias, que bien ves
que traigo los zaragüelles
con más troneras que un muro
y en cuartos los dos cuarteles,
tanto, que ya al zancarrón
de Mahoma se parecen,
que si él se tiene en el aire,
ellos también, como fuelles. (Vega Carpio, 2014a: vv. 1615-1622).

Y otro Beltrán, también criado y gracioso, nos proporciona el último ejemplo que vamos a exponer, y que sirve para ilustrar cómo el zancarrón puede también aparecer en comedias en las que no hay personajes moros, turcos o moriscos. Aunque es mucho más frecuente en ellas, el zancarrón (que no los huesos) es territorio cómico y, por tanto, propio de chistes del gracioso. En el caso de El valiente Céspedes, Beltrán lo usa para hacer una broma sobre un tema muy querido a Lope, los celos:

Digo que es verdad, señor; pero si amor es quimera, ¿sabes cómo yo quisiera comer los gustos de amor?

Sin hacer pleito civil, como pesa un carnicero una pierna de carnero para un señor alguacil. Él le quita la faldilla, 
capadura y zancarrón, y, como el triste el jabón, va en redondo la cuchilla. Esto digo yo de amor, que lo superfluo quitado, la faldilla del cuidado, lo que sobra del rigor, y el zancarrón de los celos, que es peor que el de Mahoma, ¿quién habrá que no le coma? (Vega Carpio, 1901: 201).

En conclusión, en este estudio hemos propuesto un análisis técnico, no ideológico, del uso lopesco del zancarrón de Mahoma. Así, en lugar de reprocharle a Lope un antiislamismo que, por lo demás, damos por sentado, tratamos de comprender su arte dramático a través de este tipo de escenas recurrentes o "pasos", localizando en su obra varios de ellos relacionados con el dicho zancarón y conectados con otros motivos ya estudiados, como el morisco gracioso. Nos alejamos así de críticos como Luce López-Baralt (1995: 205-206), quien en su loable empeño de reivindicar la literatura aljamiada cae en calificar a Lope de "representante de la españolidad más rancia" y de "poeta de la raza" porque se burla frecuentemente de Mahoma sacando a colación el zancarrón. Para tratar de comprender las diversas funciones de este motivo hemos recurrido a bases de datos como el CORDE y el $C D H$, gracias a las que hemos identificado la comedia lopesca como un lugar privilegiado para la aparición de menciones del zancarrón de Mahoma, esa fantástica reliquia islámica que les servía a los españoles áureos para denigrar la religión musulmana. Hemos visto de dónde procede este ridículo pernil y cómo se relaciona con la idea que presentaba al islam como un reflejo deformado de la religión cristiana, lo que explica el éxito que tuvo esta reliquia durante el Siglo de Oro. Para profundizar en el tema, hemos empleado otra base de datos, el TESO, especializada en teatro áureo, para localizar más ejemplos, obteniendo un corpus que hemos completado con nuestras lecturas hasta obtener un total de veintitrés comedias de Lope de Vega, que es, como hemos dicho, el dramaturgo más aficionado a sacar a relucir el zancarón. A continuación, hemos clasificado estas menciones según diversas variables que nos han permitido profundizar en cómo empleaba el Fénix esta reliquia. Así, hemos identificado algunos elementos de importancia, como es, por ejemplo, la diversidad de estas menciones, que oscilan entre usos abiertamente grotescos (normalmente usando la palabra zancarrón) y otros más bien tipológicos, es decir, de afán caracterizador de los musulmanes (que hablan de las reliquias del profeta refiriéndose a sus "huesos" o "cuerpo"). Además, hemos visto cómo estos usos se concentran en diversas fórmulas: los chistes del gracioso, los juramentos, las escenas en las que un musulmán reniega de su religión, las 
escenas de cristianos disfrazados de moros o turcos y, por supuesto, ese clásico de las tablas áureas que son los moriscos graciosos, los Alís o Zulemillas que mencionan el zancarrón con su español característico. El zancarrón es, en suma, una ventana que nos permite atisbar la graciosidad áurea y el arte dramático del gran Lope de Vega.

Además, y adentrándonos ahora ya sí en el terreno ideológico, podemos emplear estos datos y taxonomía para reflexionar sobre la importancia del zancarrón de Mahoma en la literatura y pensamiento áureos. En primer lugar, llama la atención lo arraigada que estaba en las tablas la idea de que el islam era una versión ridícula e invertida del cristianismo, una especie de reflejo paródico y diabólico de la verdadera religión. Por ello, las burlas hacia el zancarrón no derivan jamás en una reflexión sobre una devoción tan importante en el catolicismo áureo como eran las reliquias (Christian, 1989: 21, 123-124, 126-127, 135-139 y passim). Ello se debe, por supuesto, a que ni las tablas del corral eran el lugar apropiado para tales reflexiones ni los reinados de Felipe III y IV el momento propicio para realizarlas. Habría sido impensable siquiera tocar en una comedia un tema tan sensible y tan identificado con los intentos reformistas, y por consiguiente tan susceptible de provocar la indignación del público y las atenciones del Santo Oficio. Incluso en las obras del quinientos en las que aparece el tema, y que en las que quizás podríamos haber supuesto una inclinación mayor hacia este tipo de reflexiones, como el Viaje de Turquía, las menciones al zancarrón no invitan jamás a pensar en las reliquias cristianas. Los textos tratan unas (las mahometanas) como un reflejo grotesco de las verdaderas (las cristianas), sobre cuya virtud jamás se duda en estos foros.

En segundo lugar, podemos resaltar entre nuestras conclusiones el hecho de que, aunque la leyenda del zancarrón está evidentemente relacionado con el antiislamismo hispánico, y aunque muchos de los personajes que lo sacan a relucir son moriscos, el corpus no permite sustentar que todos autores áureos sacaran a relucir la falsa reliquia con el fin de hacer avanzar la causa de la expulsión, pues el motivo se revela tan popular en las fechas inmediatamente cercanas a la misma como en décadas anteriores y posteriores. Aunque, por supuesto, los escritores que defendían la expulsión, como Verdú, no dudaron en mentar el zancarrón, la relación no es exclusiva. El zancarrón no se usaba siempre en ese contexto concreto y siguió existiendo siglos después de consumarse la expulsión de los moriscos.

En tercer lugar, queremos subrayar que podríamos usar el zancarrón para tratar de establecer la ideología de los escritores decimonónicos y, tal vez, dieciochescos. En estos siglos la popularidad del motivo desciende notablemente, al ritmo que desaparece la amenaza militar islámica y la presión de turcos y berberiscos sobre los intereses españoles, ya directos (el Mediterráneo), ya indirectos (Europa oriental), y con este descenso destacan los escritores que todavía 
siguen recurriendo al zancarrón. Así, hemos señalado que resulta sugestivo que un autor inicialmente progresista como el duque de Rivas condene los chistes sobre el zancarrón en El moro expósito, mientras que dos atalayas del pensamiento reaccionario del XIX como son Fernán Caballero y Pereda lo usen con gusto. Sin embargo, el antimahometismo dominante en el Siglo de Oro hace difícil fijarse en la popularidad del zancarrón para deslindar los autores en rancios (por usar la terminología de López-Baralt) y progresistas, pues lo emplean muchísimos escritores, y tan variopintos como el autor del Viaje de Turquía, González de Eslava, Góngora, Lope, Quevedo o sor Juana. La mayoría de estos escritores usa el motivo del zancarrón por su potencial satírico y cómico, en el caso del Fénix siguiendo una serie de patrones que hemos trazado a lo largo de este artículo, que acabamos de resumir en el párrafo anterior y que nos permiten localizar una serie de escenas-tipo o pasos del teatro lopesco, entre las que quizás destaca la del juramento del moro o una de sus variaciones, la del juramento del cristiano disfrazado de moro. Como también hemos visto, estas escenas no significan que Lope renunciara a presentar ocasionalmente una visión más digna del zancarrón, pues en el género dramático resulta obligatorio dar lugar a cierto dialogismo y a contraponer las voces del cristiano con las del otro. El caso más llamativo de este dialogismo lo hemos localizado en Lo que hay que fiar del mundo, donde un sultán turco (Selín) contrasta las reliquias cristianas con el zancarrón (que no menciona usando este sustantivo peyorativo), que él considera mucho más milagroso y potente. El hecho de que el personaje sea un musulmán y lo directo de su ataque nos impide leer el pasaje como una reflexión sobre el uso católico de las reliquias, pero resulta interesante porque muestra el gran arraigo del motivo del zancarrón (todos los personajes, cómicos o serios, admiten su existencia) y porque pone de relieve la habilidad con la que Lope lo sabía utilizar para diseñar diversas situaciones dramáticas.

\section{OBRAS CITADAS}

Bunes Ibarra, Miguel Ángel de (1989): La imagen de los musulmanes y del norte de África en la España de los siglos XVI-XVII. Los caracteres de una hostilidad, Madrid, CSIC.

Cantar de Roldán (1983): Juan Victorio (ed.), Madrid, Cátedra.

Case, Thomas E. (1981): "El morisco gracioso en el teatro de Lope de Vega", en Manuel Criado de Val (ed.), Lope de Vega y los orígenes del teatro español, Madrid, Edi-6, pp. 785-790.

$C D H=$ Instituto de Investigación Rafael Lapesa de la Real Academia Española (2013): Corpus del Nuevo diccionario histórico $(\mathrm{CDH})$ [en línea], <http://web.frl.es/CNDHE>.

Ceballos Viro, Ignacio (2009): "El romance El Zancarrón de Mahoma y la pervivencia de una leyenda medieval", en Jesús Cañas Murillo, Francisco Javier Grande Quejigo y José Roso Díaz (eds.), Medievalismo en Extremadura: estudios sobre literatura y cultura hispánicas de la Edad Media, Cáceres, Universidad de Extremadura, pp. 305-318. 
Christian, William A. (1989): Local Religion in Sixteenth-Century Spain, Princeton, Princeton University Press.

CORDE $=$ Real Academia Española: Banco de datos (CORDE) [en línea]. Corpus diacrónico del español, <http://www.rae.es>.

Covarrubias Horozco, Sebastián de (2006): Tesoro de la lengua castellana o española, Ignacio Arellano y Rafael Zafra (ed.), Madrid, Iberoamericana.

D’Ancona, Alessandro (1888): "La leggenda di Maometto in Occidente", Atti dell'Accademia dei Lincei, IV, pp. 111-267.

Davies, Mark (2001-2017): El corpus del español, Provo, Brigham Young University, <http:// www.corpusdelespanol.org/>.

Diccionario de Autoridades (1726-1737): 3 vols., Madrid, Francisco Hierro.

Domínguez, Luis Antonio (1985): "Un motivo de polémica antimorisca «El zancarrón de Mahoma»", Revista de Folklore, XLIX, pp. 28-31.

Ferrer Valls, Teresa (1993): Nobleza y espectáculo teatral (1535-1622): estudio y documentos, Madrid, UNED.

Ferrer Valls, Teresa (2001): "Lope de Vega y la dramatización de la materia genealógica (II): lecturas de la historia", en Roberto Castilla Pérez y Miguel González Dengra (eds.), La teatralización de la historia en el Siglo de Oro español, Granada, Universidad de Granada, pp. 13-51.

Gillet, Joseph E. (ed.) (1951): Propalladia and Other Works by Torres Naharro, vol. 3, University of Pennsylvania, Philadephia.

Granja, Agustín de la (2000): “«Este paso ya está hecho»: Calderón contra los mosqueteros”, en Javier Aparicio Maydeu (ed.), Estudios sobre Calderón, Istmo Madrid, vol. 1, pp. 160-190.

Granja, Fernando de la (1968): "Milagros españoles en una obra musulmana (El «kitab Maqamic Al-Sulban» del Jazrayi)", Al-Andalus, XXXII, pp. 311-365.

Hernando Morata, Isabel (2012): “«Este paso ya está hecho»: otra vez sobre la dama triste o melancólica en Calderón”, en Carlos Mata Induráin y Adrián Sáez (eds.), Scripta manent: actas del I Congreso Internacional Jóvenes Investigadores Siglo de Oro, JISO 2011, Pamplona, Universidad de Navarra, pp. 241-254.

Herrero García, Miguel (1966): Ideas de los españoles del siglo XVII, Madrid, Gredos.

López-Baralt, Luce (1995): "«Al revés de los cristianos»: la España invertida de la literatura aljamiado-morisca", en José M. ${ }^{a}$ Díez Borque (ed.), Culturas en la Edad de Oro, Madrid, Complutense, pp. 197-222.

Morley, S. Griswold y Courtney Bruerton (1968): Cronología de las comedias de Lope de Vega. Con un examen de las atribuciones dudosas, basado todo ello en un estudio de su versificación estrófica, M. ${ }^{\mathrm{a}}$ Rosa Cartes (trad.), Madrid, Gredos.

Pedraza Jiménez, Felipe B. (2008): Lope de Vega, genio y figura, Granada, Universidad de Granada.

Perceval, José María (1988): "L'«Os» de Mahomet: à propos de pattes, de bras et autres objets putrescibles et imputrescibles", Les Temps Modernes, DVII, pp. 1-21, <http://www.materiales dehistoria.org/zancarron.htm>.

Sánchez Jiménez, Antonio (2012): "La poética de la noche en siete sonetos apelativos de Lope de Vega (Rimas, La prueba de los amigos, La noche toledana, El mayor imposible): estudio de una fórmula literaria", eHumanista, XXII, pp. 357-374.

Sánchez Jiménez, Antonio (2014): "Otro soneto apelativo a la noche en Lope de Vega: El príncipe perfeto (c. 1612-1614)", eHumanista, XXVII, pp. 407-414.

TESO = M. ${ }^{a}$ del Carmen Simón Palmer (dir.) (1997- ): Teatro Español del Siglo de Oro. Base de datos de texto completo, ProQuest LLC, <http://teso.chadwyck.com>.

Tolan, John V. (1998): "Un cadavre mutilé: le déchirement polémique de Mahomet (1)", Le Moyen Age. Revue d'histoire et de philologie, CIV, pp. 53-72. 
Tolan, John V. (1999): "Muslims as Pagan Idolaters in Chronicles of the First Crusade", en Michael Frassetto y David Blanks (eds.), Western Views of Islam in Medieval and Early Modern Europe, New York, Palgrave, 1999, pp. 97-117.

Tolan, John V. (2009): “A Life of Muhammad from Fifteenth-Century Spain”, Jerusalem Studies in Arabic and Islam, XXXVI, pp. 425-438.

Tolan, John V. (2010): "European Accounts of Muhammad's Life", en Jonathan E. Brockopp (ed.), The Cambridge Companion to Muhammad, Cambridge, Cambridge University Press, pp. 226-250.

Torres Naharro, Bartolomé de (2013): Teatro completo, Julio Vélez Sainz (ed.), Madrid, Cátedra.

Vega Carpio, Lope de (1895): "San Diego de Alcalá", en Marcelino Menéndez Pelayo (ed.), Obras de Lope de Vega publicadas por la Real Academia Española. Tomo V. Comedias de vidas de santos y leyendas piadosas (conclusión). Comedias pastoriles, Madrid, Real Academia Española, pp. 33-70.

Vega Carpio, Lope de (1899a): "El primer Fajardo", en Marcelino Menéndez Pelayo (ed.), Obras de Lope de Vega publicadas por la Real Academia Española. Tomo X. Crónicas y leyendas dramáticas de España. Cuarta sección, Madrid, Real Academia Española, pp. 1-40.

Vega Carpio, Lope de (1899b): "El sol parado", en Marcelino Menéndez Pelayo (ed.), Obras de Lope de Vega publicadas por la Real Academia Española. Tomo IX. Crónicas y leyendas dramáticas de España. Tercera sección, Madrid, Real Academia Española, pp. 39-80.

Vega Carpio, Lope de (1899c): "Los Vargas de Castilla", en Marcelino Menéndez Pelayo (ed.), Obras de Lope de Vega publicadas por la Real Academia Española. Tomo X. Crónicas y leyendas dramáticas de España. Cuarta sección, Madrid, Real Academia Española, pp. 285-324.

Vega Carpio, Lope de (1900a): "El hidalgo Bencerraje", en Marcelino Menéndez Pelayo (ed.), Obras de Lope de Vega publicadas por la Real Academia Española. Tomo XI. Crónicas y leyendas dramáticas de España. Quinta sección, Madrid, Real Academia Española, pp. 39-84.

Vega Carpio, Lope de (1900b): "El remedio en la desdicha", en Marcelino Menéndez Pelayo (ed.), Obras de Lope de Vega publicadas por la Real Academia Española. Tomo XI. Crónicas y leyendas dramáticas de España. Quinta sección, Madrid, Real Academia Española, pp. 165-206.

Vega Carpio, Lope de (1901): "El valiente Céspedes", en Marcelino Menéndez Pelayo (ed.), Obras de Lope de Vega publicadas por la Real Academia Española. Tomo XII. Crónicas y leyendas dramáticas de España. Sexta sección, Madrid, Real Academia Española, pp. 187-230.

Vega Carpio, Lope de (1917a): "La difunta pleiteada", en Emilio Cotarelo y Mori (ed.), Obras de Lope de Vega publicadas por la Real Academia Española (Nueva Edición), Madrid, Real Academia Española, vol. IV, pp. 543581.

Vega Carpio, Lope de (1917b): "La divina vencedora", en Emilio Cotarelo y Mori (ed.), Obras de Lope de Vega publicadas por la Real Academia Española (Nueva Edición), Madrid, Real Academia Española, vol. IV, pp. 616-654.

Vega Carpio, Lope de (1929): "La boba para los otros y discreta para sí", en Emilio Cotarelo y Mori (ed.), Obras de Lope de Vega publicadas por la Real Academia Española (Nueva Edición), Madrid, Real Academia Española, vol. XI, pp. 472-507.

Vega Carpio, Lope de (1930): "Ya anda la de Mazagatos", en Emilio Cotarelo y Mori (ed.), Obras de Lope de Vega publicadas por la Real Academia Española (Nueva Edición), Madrid, Real Academia Española, vol. X, pp. 492-539.

Vega Carpio, Lope de (1965): "Los mártires de Madrid", en Marcelino Menéndez Pelayo (ed.), Obras de Lope de Vega. XI. Comedias de vidas de santos. II, Madrid, Atlas, pp. 215-267.

Vega Carpio, Lope de (2008a): "Lo que hay que fiar del mundo", José Enrique Laplana Gil y Luis Sánchez Laílla (eds.), en José Enrique Laplana Gil (coord.), Comedias de Lope de Vega. Parte XII, vol. II, Madrid, Gredos, pp. 337-484.

Vega Carpio, Lope de (2008b): "Los Porceles de Murcia", Francisco Lobera Serrano (ed.), en Enrico di Pastena (coord.), Comedias de Lope de Vega. Parte VII, Lérida, Milenio, vol. II, pp. $705-834$. 
Vega Carpio, Lope de (2008c): "Viuda, casada y doncella", Ronna S. Feit y Donald McGrady (ed.), en Enrico di Pastena (coord.), Comedias de Lope de Vega. Parte VII, Lérida, Milenio, 2008, vol. III, pp. 1097-1240.

Vega Carpio, Lope de (2009): “Angélica en el Catay”, Marcella Trambaioli (ed.), en Rafael Ramos (coord.), Comedias de Lope de Vega. Parte VIII, Lérida, Milenio, vol. III, pp. 1387-1502.

Vega Carpio, Lope de (2014a): "El alcalde mayor", José Enrique López Martínez (ed.), en Natalia Fernández Rodríguez (coord.), Comedias de Lope de Vega. Parte XIII, Madrid, Gredos, vol. II, pp. 3-164.

Vega Carpio, Lope de (2014b): "Los esclavos libres", Ely Treviño (ed.), en Natalia Fernández Rodríguez (coord.), Comedias de Lope de Vega. Parte XIII, Madrid, Gredos, vol. I, pp. 537709.

Vega Carpio, Lope de (2015): "El cuerdo loco”, Antonio Sánchez Jiménez y Adrián J. Sáez (eds.), en José Enrique López Martínez (ed.), Comedias de Lope de Vega. Parte XIV, Madrid, Gredos, vol. II, pp. 725-910.

Vega Carpio, Lope de (2016a): "El favor agradecido", Raúl Orellana (ed.), en Luis Sánchez Laílla (coord.), Comedias de Lope de Vega. Parte XV, Madrid, Gredos, vol. I, pp. 875-1034.

Vega Carpio, Lope de (2016b): "La Santa Liga", Juan Udaondo Alegre (ed.), en Luis Sánchez Laílla (coord.), Comedias de Lope de Vega. Parte XV, Madrid, Gredos, vol. I, pp. 689-874.

Vega Carpio, Lope de (en prensa a): "La campana de Aragón”, Diego Símini (ed.), en Antonio Sánchez Jiménez y Adrián J. Sáez (coords.), Comedias de Lope de Vega. Parte XVIII, Madrid, Gredos.

Vega Carpio, Lope de (en prensa b): "La pobreza estimada", Ignacio García Aguilar (ed.), en Antonio Sánchez Jiménez y Adrián J. Sáez (coords.), Comedias de Lope de Vega. Parte XVIII, Madrid, Gredos.

Verdú, fray Blas (1612): Engaños y desengaños del tiempo. Con un Discurso de la expulsión de los moriscos de España, Barcelona, Sebastián Matheuad/Miguel Manescal.

Viaje de Turquía (2000): Marie-Sol Ortola (ed.), Madrid, Castalia.

Fecha de recepción: 23 de mayo de 2017

Fecha de aceptación: 8 de agosto de 2017 